\title{
Adsorção de azul de metileno por meio de resíduos de Poincianella pluviosa var. peltophoroides (Benth.) L.P. Queiroz
}

O setor têxtil é responsável pela geração de efluentes com corantes sintéticos, como o azul de metileno, que por sua vez são lançados aos corpos hídricos afetando a biota local. A sibipiruna é comumente utilizada como arborização urbana, sendo que suas podas podem ser transformadas em biossorventes devido às suas características lignocelulósicas, agregando assim valor econômico para este tipo de resíduo sólido. Este trabalho teve como objetivo apresentar o estudo da adsorção do corante azul de metileno através do biossorvente obtido pela poda de sibipiruna. Para a obtenção do biossorvente, o material passou por um tratamento térmico em que foi transformado em carvão. Após o tratamento, foram feitas as análises de espectroscopia Raman e MEV, além dos estudos cinéticos e as isotermas. A espectroscopia Raman mostrou que o carvão é um material grafítico não perfeito e o MEV apresentou seu alto grau de porosidade. $O$ estudo cinético mostrou que o carvão tem um tempo ótimo de adsorção de 240 minutos e eficiência máxima de $98 \%$, além disso, o modelo que melhor se ajustou aos dados foi o modelo de pseudo-segunda ordem. Sobre a isoterma, os dados foram melhor ajustados pelo modelo de Langmuir, representando assim que o processo de adsorção é favorável. Além disso, o valor apresentado para o fator de separação indica que o processo de adsorção avaliado neste trabalho é favorável. Portanto, o uso da poda de sibipiruna mostrou-se eficiente e podendo, assim, ser utilizado como alternativa para tratamento de efluentes contaminados com corantes.

\section{Adsorption of methylene blue through waste from Poincianella pluviosa var. peltophoroides (Benth.) L.P. Queiroz}

\begin{abstract}
The textile sector is currently responsible for generation of effluents with synthetic dyes, such as methylene blue, which in turn are released to water bodies affecting the local biota. The sibipiruna is commonly used as urban afforestation, thus its pruning can be transformed into biosorbs due to its lignocellulosic characteristics, thus adding economic value to this type of solid waste. This paper aims to present the study of the adsorption of methylene blue dye through the biosorbent obtained by pruning sibipiruna. To obtain the biosorbent, the material underwent a heat treatment in which it was transformed into coal. After treatment, Raman and SEM spectroscopy analyzes were performed, as well as kinetic studies and isotherms. Raman spectroscopy showed that charcoal is a nonperfect graphite material and SEM presented its high degree of porosity. The kinetic study showed that the coal has an optimum adsorption time of 240 minutes and a maximum efficiency of $98 \%$. Moreover, the model that best fit the data was the pseudo-second order model. Regarding the isotherm, the data were better adjusted by the Langmuir model, thus representing that the adsorption process is favorable. Moreover, the value presented for the separation factor indicates that the adsorption process evaluated in this work is favorable. Therefore, the use of sibipiruna pruning proved to be efficient and can thus be used as an alternative for treatment of dyes-contaminated effluents.
\end{abstract}

Keywords: Biosorbent; Sibipiruna; Methylene Blue.

Topic: Engenharia Sanitária

Reviewed anonymously in the process of blind peer.
Received: 04/06/2021

Approved: 26/06/2021 lago Rosa Felberg Teixeira (D)

Universidade Tecnológica Federal do Paraná, Brasil

http://lattes.cnpq.br/5586718083117248

http://orcid.org/0000-0001-8441-0207

iagorft@hotmail.com

Laís Gimenes Vernasqui

Instituto Nacional de Pesquisas Espaciais, Brasil

http://lattes.cnpq.br/9470290295051445

http://orcid.org/0000-0002-7896-8383

laisvernasqui@gmail.com

Nathalia Bordon Pironato Sia

Universidade Tecnológica Federal do Paraná, Brasil

http://lattes.cnpq.br/0273395515724294

nathaliasia@hotmail.com
Flavia Vieira da Silva Medeiros (iD

Universidade Tecnológica Federal do Paraná, Brasil

http://lattes.cnpq.br/8298141172237555

http://orcid.org/0000-0001-6490-8876

flaviav@utfpr.edu.br
Referencing this:

TEIXEIRA, I. R. F.; VERNASQUI, L. G.; SIA, N. B. P.; MEDEIROS, F. V. S.. Adsorção de azul de metileno por meio de resíduos de Poincianella pluviosa var. peltophoroides (Benth.) L.P. Queiroz. Revista Ibero Americana de Ciências Ambientais, v.12, n.6, p.297-306, 2021. DOI: http://doi.org/10.6008/CBPC2179-6858.2021.006.0025 


\section{INTRODUÇÃO}

O setor têxtil, do ponto de vista ambiental, é caracterizado por um elevado consumo de água, bem como pela geração de resíduos sólidos, emissões atmosféricas e efluentes líquidas que possuem grande potencial de poluição (SILVA et al., 2017). Portanto, a necessidade do desenvolvimento de novas tecnologias para o tratamento de resíduos está cada vez maior. A questão do descarte de resíduos no meio ambiente ainda é um problema e em muitos casos não há protocolos eficientes que propiciem o controle absoluto (PIZATO et al., 2017).

Estima-se que aproximadamente 20 t/ano de corantes são consumidos pela indústria têxtil, e cerca de $20 \%$ destes são descartados como efluentes. O principal motivo desta perda está relacionado à incompleta fixação do corante à fibra do tecido durante o processo de tingimento (HONORATO et al., 2015). Entre os corantes mais utilizados destaca-se a classe dos reativos, dentre eles o azul de metileno, um corante catiônico do grupo das fenotiazinas, empregado na indústria têxtil no tingimento de tecidos de algodão e lãs, gerando então um efluente que afeta não só a transparência das águas, mas também limita a passagem de radiação solar diminuindo a atividade fotossintética natural provocando alterações na biota aquática, originando toxicidade aguda e crônica de ecossistemas aquáticos (OLIVEIRA et al., 2018).

O método da adsorção vem sendo muito empregado no tratamento de efluentes corados devido ao seu baixo custo e facilidade de operação. Esta técnica consiste na remoção de contaminantes pela interação entre o corante e o material adsorvente. Porém materiais de alta capacidade adsortiva, como carvão ativado, tem alto custo de produção, tornando-se muitas vezes inviável (HONORATO et al., 2015). Desta forma, Honorato et al. (2015), também dizem que se abre espaço para pesquisas de novos materiais adsorventes como materiais biológicos e subprodutos agrícolas visando a substituição do carvão ativado.

A adsorção é uma operação de transferência de massa, a qual estuda a habilidade de certos sólidos em concentrar na sua superfície determinadas substâncias existentes em fluidos líquidos ou gasosos, possibilitando a separação dos componentes desses fluidos. Uma vez que os componentes adsorvidos, concentram-se sobre a superfície externa, quanto maior for está superfície externa por unidade de massa sólida, tanto mais favorável será a adsorção, por isso, geralmente os adsorventes são sólidos com partículas porosas (NASCIMENTO et al., 2014).

Segundo Nascimento et al. (2014), a cinética de adsorção é a taxa de remoção do adsorvato na fase fluida em relação ao tempo, envolvendo a transferência de massa de um ou mais componentes contidos em uma massa líquida externa para o interior da partícula do adsorvente, os quais deverão migrar através dos macroporos até as regiões mais interiores desta partícula. Entre os modelos cinéticos disponíveis, pseudoprimeira ordem e pseudo segunda ordem são os mais utilizados para correlacionar dados de adsorção cinética de substâncias perigosas em nanocelulose (PUTRO et al., 2017).

Isotermas são diagramas que mostram a variação da concentração de equilíbrio no sólido adsorvente com a pressão parcial ou concentração da fase líquida, em uma determinada temperatura. Os gráficos assim obtidos podem apresentar-se de várias formas, fornecendo informações importantes sobre o mecanismo de 
adsorção. Ao analisarmos as diversas formas de isotermas, podemos obter informações extremamente relevantes sobre o processo de adsorção (NASCIMENTO et al., 2014).

Nos últimos anos, a pesquisa sobre a utilização de resíduos agroindustriais para a remediação de ambientes contaminados pelo processo de adsorção vem ganhando destaque devido à elevada quantidade de resíduos que a agroindústria produz, que por sua vez podem constituir sérios problemas de disposição final (OLIVEIRA et al., 2018). O uso da sibipiruna foi escolhido pois seu uso como arborização urbana gera resíduos, acarretando problemas em sua destinação final como aterros sanitários e composteiras municipais, entretanto o uso de seus resíduos através da poda tratada, pode ser utilizado para agregar valor econômico em tratamentos de efluentes.

A Poincianella pluviosa var. peltophoroides (Benth.) L. P. Queiroz, conhecida vulgarmente como sibipiruna, sebipira ou sepipiruna, é uma planta pertencente à família Fabaceae que pode variar sua altura de 8 a 16 metros, com tronco de 30 a 40 centímetros de diâmetro, revestido por casca com ritidoma escamoso, possui flores amarelas em racemos apicais e frutos vagens deiscentes achatadas. Sua madeira é pesada, dura, de textura média e de média durabilidade natural (LORENZI, 2008). Lorenzi (2008) diz também que a sibipiruna ocorre na região da Mata Atlântica do Rio de Janeiro, no sul da Bahia e no Pantanal matogrossense.

Desta forma, o presente trabalho tem como objetivo geral estudar o potencial de biossorção do azul de metileno por meio de adsorvente preparado a partir de resíduos de poda da Poincianella pluviosa var. peltophoroides (Benth.) L.P. Queiroz em amostras aquosas. Além disso, como objetivos específicos preparar o adsorvente a partir da poda da Poincianella pluviosa var. peltophoroides (Benth.) L.P. Queiroz por meio de tratamento térmico; realizar a caracterização do adsorvente; realizar testes de equilíbrio de adsorção; realizar o estudo cinético de biossorção do azul de metileno; e realizar testes de isotermas de adsorção do azul de metileno.

\section{MATERIAIS E MÉTODOS}

Os experimentos referentes às seções 2.1, 2.2, 2,4 e 2.5 foram realizados no Núcleo de Pesquisa em Engenharia Ambiental (NUPEA) da Universidade Tecnológica Federal do Paraná - Campus Campo Mourão.

\section{Preparo da Poincianella pluviosa var. peltophoroides (Benth.) L. P. Queiroz}

As amostras de Sibipiruna foram obtidas por meio de coleta no campus da Universidade Tecnológica Federal do Paraná - Campo Mourão, e posteriormente trituradas por um moinho de facas e secas em estufa de circulação forçada a $50^{\circ} \mathrm{C}$ por uma semana.

\section{Tratamento térmico da Poincianella pluviosa var. peltophoroides (Benth.) L. P. Queiroz}

O tratamento térmico foi realizado em forno mufla a $500 \stackrel{\circ}{ } \mathrm{C}$ durante um período de 2 horas. Após atingir a temperatura ambiente, o adsorvente foi colocado em um dessecador até atingir a temperatura ambiente e então foi separado por tamanho de partícula por meio de peneiramento com malha de 35 mesh. 
Após o tratamento térmico, o carvão resultante passou por um processo de lavagem com água destilada para que pudessem ser removidos sedimentos que poderiam influenciar nos resultados dos experimentos. Então, após a lavagem, o material passou novamente por um processo de secagem na estufa de circulação forçada.

\section{Caracterização do biossorvente}

O fenômeno denominado espalhamento Raman pode ser retratado como: se uma onda eletromagnética atinge a superfície de um meio, uma fração da luz é refletida enquanto que o resto é transmitido para dentro do material. Portanto, da parcela da radiação transmitida através da superfície, uma fração desta é absorvida na forma de calor e outra é retransmitida na forma de luz espalhada. A luz emergente apresenta em seu bojo uma pequena parcela composta de frequências diferentes daquele incidente (RODRIGUES et al., 2012).

As medidas de espalhamento Raman foram realizadas utilizando um espectrômetro Renishaw Raman série H02910 acoplado a um microscópio óptico Leica DMLM com radiação incidente de $1 \mu \mathrm{m}$, pelo uso de laser de $514 \mathrm{~nm}$ como fonte de excitação, com potência de $20 \mathrm{nW}$. Os espectros foram obtidos na região de 2000 - 200 cm-1. As análises foram realizadas no Laboratório Associado de Sensores e Materiais (LAS) do Instituto Nacional de Pesquisas Espaciais (INPE), no município de São José dos Campos - SP.

Com o propósito de caracterizar o biossorvente de maneira estrutural, foi realizado a microscopia eletrônica de varredura com o auxílio do equipamento MIRA3 - TESCAN localizado no Laboratório Associado de Sensores e Materiais (LAS) do Instituto Nacional de Pesquisas Espaciais (INPE), no município de São José dos Campos - SP. Por meio deste equipamento foram obtidas imagens do biossorvente com tratamento térmico.

\section{Estudo cinético da biossorção de azul de metileno}

As análises de adsorção foram realizadas utilizando $50 \mathrm{~mL}$ da solução de corante em concentração de $10 \mathrm{mg} / \mathrm{L}$ diluídos com água destilada. Os estudos cinéticos foram realizados em duplicata, adaptando-se a metodologia utilizada por Zhou et al. (2018). Portanto, amostras de $1 \mathrm{~g}$ do biossorvente foram colocadas em contato com $50 \mathrm{~mL}$ da solução de azul de metileno na concentração $10 \mathrm{mg} / \mathrm{L}$ em Erlenmeyers de $100 \mathrm{~mL}$, sob agitação de $150 \mathrm{rpm}$ a 35으 por tempos determinados de 1, 5, 10, 20, 30, 60, 120, 240, 360, 480, 720 e 1440 minutos. Após o processo de adsorção, a concentração final do corante em solução foi determinada utilizando um espectrofotômetro UV-VIS a $665 \mathrm{~nm}$, sendo esse o comprimento de onda do azul de metileno de acordo com Oliveira et al. (2018).

E então com a ajuda dos modelos de pseudo-primeira ordem, proposto inicialmente por Lagergren em 1898 e de pseudo-segunda ordem como proposto por Ho e McKay em 1998, Equações 1 e 2, respectivamente, apresentados anteriormente, e utilizando suas respectivas formas linearizadas, foram determinadas as constantes cinéticas (fisiossorção e quimiossorção), capacidade de adsorção no equilíbrio e o tempo ótimo de adsorção. 0 modelo que melhor representou os dados experimentais foi então escolhido 
a partir do coeficiente de determinação $\left(R^{2}\right)$ em conjunto com a avaliação do qe calculado.

\section{Isotermas de adsorção de azul de metileno}

Para os experimentos de equilíbrio, foram construídas as isotermas de adsorção utilizando a metodologia adaptada de Zhou et al. (2018), em que a temperatura foi de $35{ }^{\circ} \mathrm{C}$ e o pH de 5 , e o tempo utilizado foi o considerado ótimo a partir do estudo cinético. Foram utilizadas várias concentrações iniciais, variando entre 1 e $50 \mathrm{mg} / \mathrm{L}$ de azul de metileno, sendo elas: $1 ; 2,5 ; 5 ; 7,5 ; 10 ; 20 ; 30$ e $50 \mathrm{mg} / \mathrm{L}$. Os modelos utilizados para o ajuste dos dados e adsorção seguiram os modelos de Langmuir, Freundlich e foi determinado também o fator de separação $\left(R_{\mathrm{L}}\right)$, apresentados no item 4.5 , dados respectivamente pelas Equações 3, 4 e 5.

\section{RESULTADOS}

\section{Espectroscopia Raman}

Após análise dos dados e construção dos gráficos, notou-se que a amostra gerou um sinal Raman com bandas definidas (Figura 1). Portanto, é possível verificar a presença de ambas as bandas características de um material grafítico não perfeito: a banda D e a banda $G$.

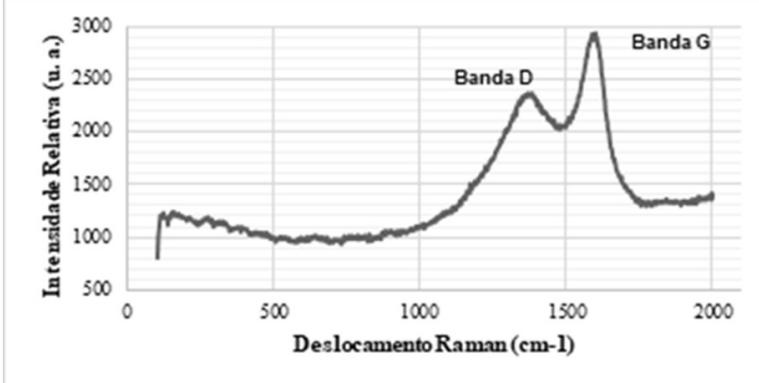

Figura 1: Gráfico resultante da Espectroscopia Raman.

\section{Microscopia Eletrônica de Varredura (MEV)}

Com as imagens obtidas através da microscopia eletrônica de varredura (MEV) é possível observar alta porosidade no material. A Figura 2 apresenta as imagens referentes ao carvão produzido com ampliação de 500 x. A Figura 3 apresenta o carvão com 5.000 x de ampliação.

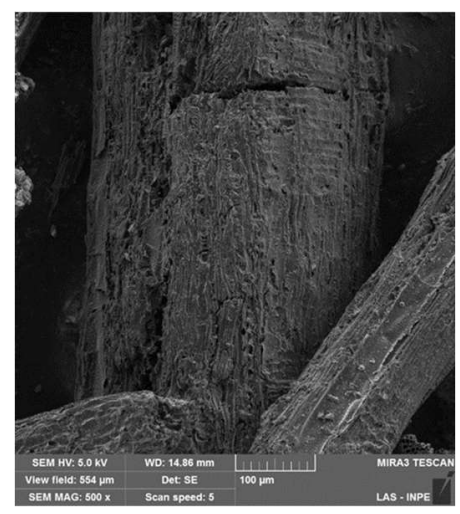

Figura 2: MEV com 500 x de ampliação do biossorvente com tratamento térmico.

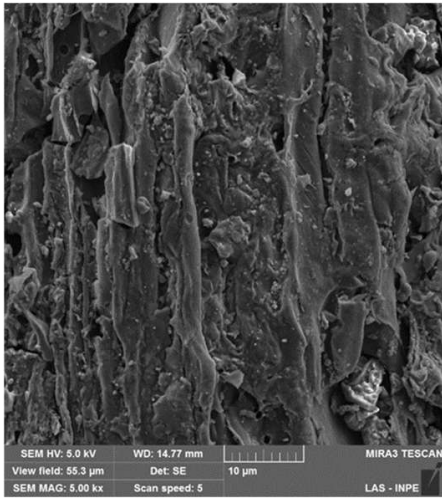

Figura 3: MEV com 5.000 x de ampliação do biossorvente com tratamento térmico. 


\section{Estudo cinético da biossorção do azul de metileno}

De acordo com Zeferino et al. (2013), a cinética de adsorção é determinada para estabelecer o tempo de contato ideal entre o adsorvente e o adsorbato. Os dados obtidos por meio da metodologia proposta estão apresentados nas Figura 4. A Figura 5 mostra a diminuição da concentração de azul de metileno ao decorrer do tempo. Os dados experimentais foram ajustados aos modelos cinéticos e os valores de $\mathrm{R}^{2}$, das constantes de equilíbrio e de $\mathrm{q}_{\mathrm{e}}$ calculado para o modelo de pseudo-primeira ordem e para o de pseudosegunda ordem são apresentados na Tabela 1.

Tabela 1: Resultados dos modelos cinéticos.

\begin{tabular}{l|l|l}
\hline & PSEUDO-PRIMEIRA ORDEM & PSEUDO-SEGUNDA ORDEM \\
\hline $\mathbf{q}\left(\mathbf{m g}^{-1} \mathbf{~}^{-1}\right)$ & 14,4569 & 0,4787 \\
\hline $\mathbf{k}_{\mathbf{1}}\left(\mathbf{m i n}^{-1}\right)$ & 0,0298 & \\
\hline $\mathbf{k}_{\mathbf{2}}(\mathbf{g} / \mathbf{m g} \cdot \mathbf{m i n})$ & & 1,4425 \\
\hline $\mathbf{R}^{\mathbf{2}}$ & 0,9639 & 1 \\
\hline
\end{tabular}

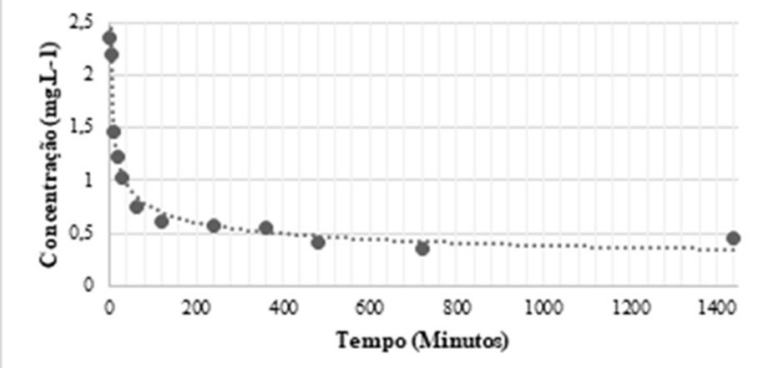

Figura 4: Concentração de azul de metileno ao decorrer do tempo.

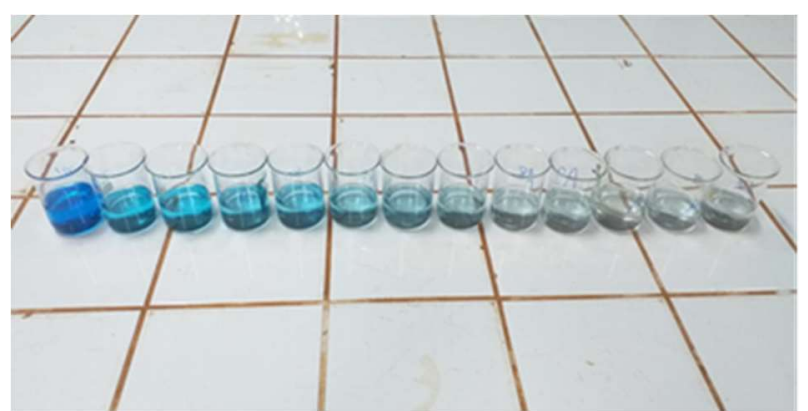

Figura 5: Amostras após tratamento com adsorvente produzido.

A partir dos dados obtidos, vários modelos cinéticos podem ser utilizados para examinar o mecanismo controlador do processo de adsorção, contudo, os modelos empregados com maior frequência são os de pseudo-primeira ordem e de pseudo-segunda ordem, Equação 1 e 2 respectivamente (ROCHA et al., 2012). 0 ajuste dos dados obtidos para estes modelos é apresentado nas Figuras 6 e 7, respectivamente.

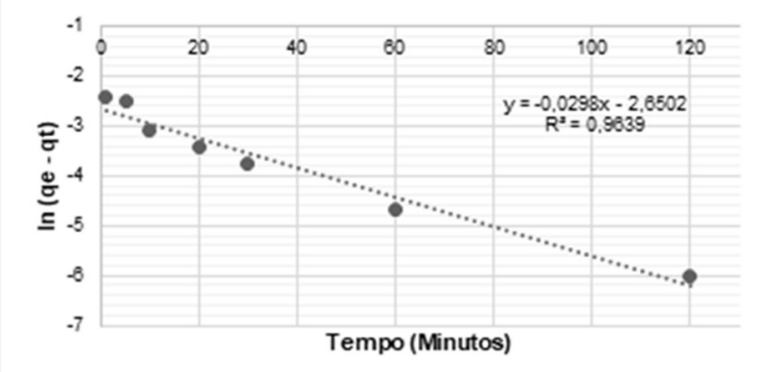

Figura 6: Resultados da cinética de pseudo-primeira ordem.

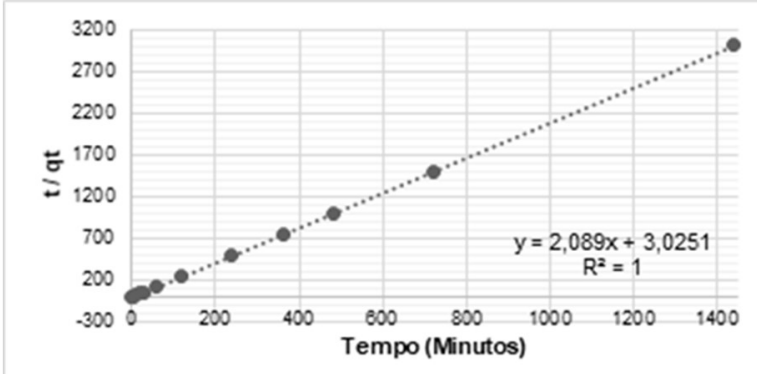

Figura 7: Resultados da cinética de pseudo-segunda ordem.

\section{Isotermas de adsorção do azul de metileno}

Os dados obtidos para a isoterma de equilíbrio estão apresentados na Figura 8. A Figura 9 apresenta as amostras após o tratamento com carvão produzido, e atrás destas estão apresentadas as soluções com concentração inicial para possibilitar a observação do contraste de cores. 


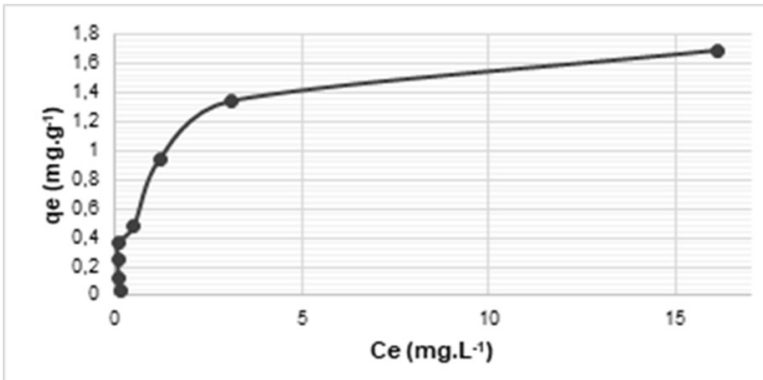

Figura 8: Resultados da isoterma de adsorção de azul de metileno com o biossorvente produzido.

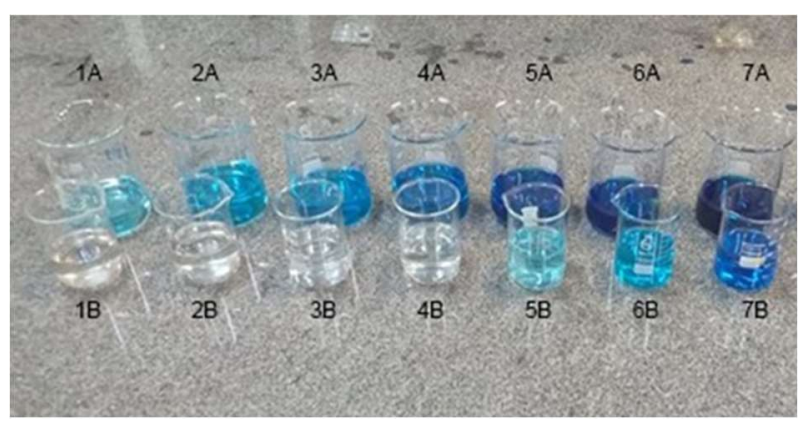

Figura 9: Amostras com concentrações iniciais de azul de metileno em mg/L (1A) 1 ; (2A) 2,5; (3A) 5; (4A) 7,5; (5A) 20; (6A) 30; (7A) 50 e amostras $B$ com respectivas concentrações finais após tratamento com o biossorvente produzido.

Os dados experimentais apresentados, foram ajustados aos modelos de Langmuir e Freundlich, utilizando as respectivas Equações 3 e 4 linearizadas, resultando assim nos gráficos apresentados nas Figuras 10 e 11. Ainda, por meio do modelo de Langmuir (Equação 5) também foi possível determinar o coeficiente de separação $\left(R_{L}\right)$, sendo que o valor obtido neste trabalho foi de 0,5091 .

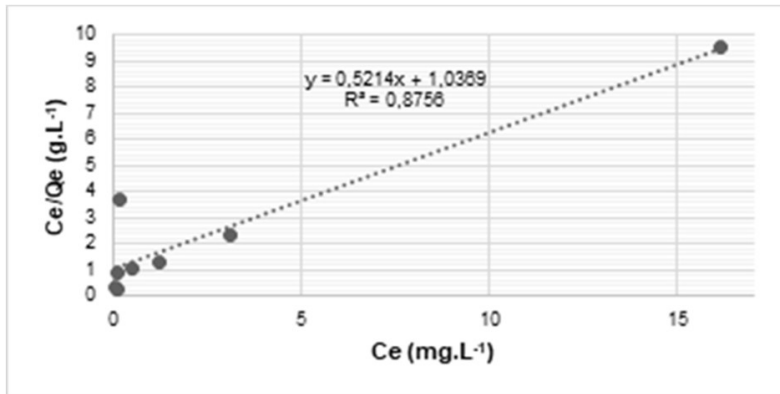

Figura 10: Ajuste ao modelo de Langmuir.

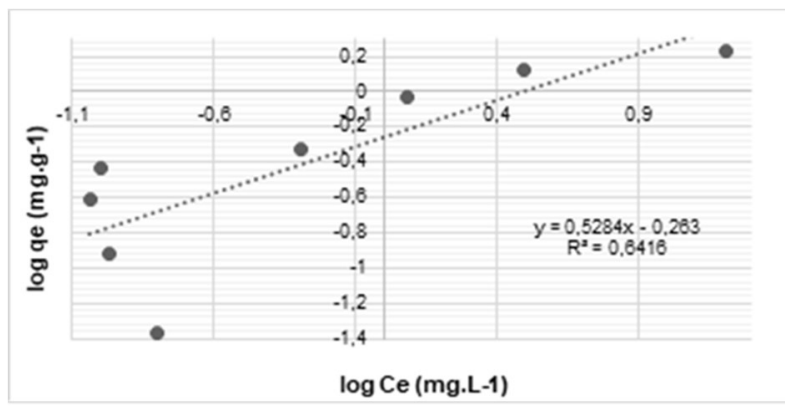

Figura 11: Ajuste ao modelo de Freundlich

\section{DISCUSSÃO}

\section{Espectroscopia Raman}

Para a obtenção de um grafite perfeito, apenas uma banda localizada em torno de $1580 \mathrm{~cm}^{-1}$ é vista, apontada como banda G, é causada devido a vibração no modo E2g. A banda de defeitos, ou também chamada de banda $D$, é outra banda comum de materiais grafíticos, localizada em torno de $1350 \mathrm{~cm}^{-1}$. Essa banda é relacionada as falhas no plano que geram vibração no modo A1g, além disso, caracterizam um material imperfeito, de forma que em uma análise de um material perfeitamente grafítico, essa banda não deve ser vista (ANGELO, 2014).

$O$ aparecimento da banda $D$ nos resultados apontam que a temperatura usada no tratamento térmico é abaixo da necessária para a obtenção de grafite, indicando, portanto, a formação de um biocarvão e não de carvão ativado. De encontro com os resultados obtidos, Rocha et al. (2006) afirma que a temperatura ideal para obter um carvão ativado é de $720^{\circ} \mathrm{C}$, superior à temperatura utilizada no tratamento térmico neste trabalho $\left(500^{\circ} \mathrm{C}\right)$. 


\section{Microscopia Eletrônica de Varredura (MEV)}

Com as imagens obtidas através da microscopia eletrônica de varredura (MEV) é possível observar alta porosidade no material. A Figura 2 e 3, fortalecem a visualização da elevada quantidade de poros disponíveis no biossorvente com tratamento.

\section{Estudo cinético da biossorção do azul de metileno}

O tempo total de amostragem foi de 1440 minutos ( 24 horas), em que foi possível observar que a taxa de adsorção aumenta até o tempo de 240 minutos, após esse tempo a concentração de azul de metileno na solução sofre apenas um ligeiro aumento. Observa-se também que a taxa de adsorção chega até $98 \%$ neste tempo. Tendo em vista os resultados, 240 minutos foi aceito como o tempo de equilíbrio. Além da diminuição da concentração do corante comprovada através do espectrofotômetro, foi possível observar também a diminuição da coloração azul na solução preparada, como mostrado na Figura 5. A primeira amostra (da esquerda para direita) representa a solução sem tratamento com carvão produzido, para que pudesse ilustrar o contraste em relação aos tempos de contato com o adsorvente. Nota-se também, uma mudança na coloração da solução a partir do primeiro tempo.

A partir dos dados obtidos, é possível observar que o modelo de pseudo-segunda ordem é o que melhor se ajusta aos dados experimentais devido ao valor de $\mathrm{R}^{2}$ igual a 1 , e além disso, é possível notar também que o valor de $q_{e}$ calculado por esse modelo é $0,4787 \mathrm{mg} \cdot \mathrm{g}^{-1}$, próximo ao $\mathrm{q}_{\mathrm{e}}$ experimental, que é 0,47185 mg.g $\mathrm{g}^{-1}$. Diferente do modelo de pseudo-primeira ordem, que apesar de seu $\mathrm{R}^{2}$ ser próximo ao valor 1,0, o qe calculado para este modelo foi de $14,4569 \mathrm{mg} \cdot \mathrm{g}^{-1}$.

Resultados semelhantes foram encontrados na literatura. Honorato et al. (2015) avaliou a biossorção de azul de metileno utilizando resíduos agroindustriais e também observou em seus resultados que o modelo de pseudo-segunda ordem se ajustava melhor aos dados experimentais. Oliveira et al. (2018), também observaram que os dados experimentais foram melhor ajustados pelo modelo de pseudo-segunda ordem para a biossorção utilizando mesocarpo de coco verde para remoção do corante azul de metileno.

\section{Isotermas de adsorção do azul de metileno}

Diante dos dados coletados, é possível observar a relação entre a quantidade adsorvida $\left(q_{e}\right)$ e a concentração final de adsorbato $\left(C_{\mathrm{e}}\right)$. De acordo com a Figura 8, é possível observar que a isoterma obtida indica que o processo de adsorção é favorável. Na Figura 9, é possível verificar que até a concentração 7,5 $\mathrm{mg} / \mathrm{L}$ (do meio na imagem), as amostras após o tratamento praticamente não apresentam cor azul. Os dados da amostra da concentração de $10 \mathrm{mg} / \mathrm{L}$ foram aproveitados do experimento anterior.

De acordo com os ajustes realizados, observa-se que o modelo de Langmuir é o que melhor descreve os dados obtidos, uma vez que o valor para a capacidade máxima de adsorção ( $q_{m}$ ) que este modelo indica $(0,5028 \mathrm{mg} / \mathrm{g})$ é o que mais se aproxima da capacidade máxima no equilíbrio de adsorção alcançada experimentalmente $(0,4718 \mathrm{mg} / \mathrm{g})$. Além disso, os valores de $\mathrm{R}^{2}$ encontrados confirmam que o modelo que 
melhor ajusta os dados experimentais é aquele apresentado pela isoterma de Langmuir.

Tendo em vista que o processo é favorável quando $0<\mathrm{R}_{\mathrm{L}}<1$, é possível afirmar que o processo de adsorção de azul de metileno por meio do carvão produzido de Poincianella pluviosa var. peltophoroides é favorável. O modelo de Freundlich apresentou-se também favorável, pois o valor obtido para a constante de Freundlich, n, foi de 1,8925, e de acordo com Nascimento et al. (2014), uma adsorção favorável tende a ter um valor de n entre 1 e 10, ou seja, quanto maior o valor de n, mais forte a interação entre o adsorvato e o adsorvente. Devido ao n estar muito próximo a 1 e o $\mathrm{R}^{2}$ ser menor que o modelo anteriormente apresentado, optou-se por escolher o modelo de Langmuir. Andia (2009), diz em seu artigo que o modelo de Langmuir parte das suposições em que a superfície do adsorvente contém número fixo de sítios de adsorção, que todas as espécies adsorvidas interagem somente com um sítio e não entre si, que a adsorção é limitada à monocamada, além disso, a energia de adsorção de todos os sítios é idêntica e independente da presença de espécies adsorvidas as vizinhanças dos sítios e por fim que adsorção é reversível.

\section{Equações}

$$
\begin{aligned}
& \log \left(q_{e}-q_{t}\right)=\log q_{e}\left(\begin{array}{c}
k_{1} \times t \\
2,303
\end{array}\right) \\
& \frac{t}{q_{t}}=\frac{1}{k_{2} \times q_{e}^{2}}+\frac{1}{q_{e}} \\
& \frac{C_{e}}{q_{e}}=\frac{1}{q_{m} \times K_{L}}+\frac{C_{e}}{q_{m}} \\
& \log q_{e}=\log K_{F}+{ }_{n}^{1} \log C_{e} \\
& R_{L}=\frac{1}{1+K_{L} * C_{0}}
\end{aligned}
$$

\section{CONCLUSÕES}

Tendo em vista os resultados obtidos no presente estudo, obteve-se uma taxa de remoção de $98 \%$ de azul de metileno pelo resíduo de poda proveniente da Poincianella pluviosa var. peltophoroides (Benth.) L. P. Queiroz, mostrando assim seu potencial de adsorção.

A Espectroscopia Raman mostrou que o carvão desenvolvido é um material grafítico não perfeito e o MEV apresentou que ele tem alto grau de porosidade, auxiliando assim na sua eficiência de adsorção.

Sobre o estudo cinético, foi possível observar que o melhor tempo de adsorção foi de 240 minutos (4 horas), adotando esse como tempo de equilíbrio. Além disso, o modelo que melhor se ajustou aos dados foi o modelo de pseudo-segunda ordem.

Em relação à isoterma obtida, os dados foram melhor ajustados pelo modelo de Langmuir, representando assim que o processo de adsorção é favorável, representa também que a superfície do adsorvente contém número fixo de sítios de adsorção, que todas as espécies adsorvidas interagem somente 
com um sítio e não entre si, que a adsorção é limitada à monocamada, além disso, a energia de adsorção de todos os sítios é idêntica e independente da presença de espécies adsorvidas as vizinhanças dos sítios e por fim que adsorção é reversível. Além disso, o valor apresentado para o fator de separação também indica que o processo de adsorção avaliado neste trabalho é favorável.

Portanto, diante dos dados apresentados, podemos afirmar que a poda de Poincianella pluviosa var. peltophoroides (Benth.) L. P. Queiroz, que é um resíduo sólido de uma espécie muito utilizada em arborização no país, que apresentou capacidade de adsorção de azul de metileno, agregando seu valor e podendo ser utilizado como alternativa para tratamento de efluentes contaminados com corantes.

\section{REFERÊNCIAS}

ANDIA, J. P. M.. Remoção de Boro de Águas e Efluentes de Petróleo por Adsorção. Tese (Doutorado em Engenharia de Materiais e de Processos Químicos e Metalúrgicos) Pontifícia Universidade Católica de Rio de Janeiro, Rio de Janeiro, 2009.

ANGELO, L. C.. Estudo de rotas de funcionalização de finos de carvão vegetal para desenvolvimento de condicionador orgânico de solos. Tese (Doutorado em Química) Universidade Federal do Paraná, Curitiba, 2014.

HONORATO, A. C.; MACHADO, J. M.; CELANTE, G.; BORGES, W. G. P.; DRAGUNSKI, D. C.; CAETANO, J.. Biossorção de azul de metileno utilizando resíduos agroindustriais. Revista Brasileira de Engenharia Agrícola e Ambiental, v.19, n.7, p.705-710, 2015. DOI: http://doi.org/10.1590/18071929/agriambi.v19n7p705-710

LORENZI, H.. Árvores Brasileiras: Manual de Identificação e Cultivo de Plantas Arbóreas Nativas do Brasil. 5 ed. Nova Odessa: Instituto Plantarum de Estudos da Flora Ltda., 2008.

NASCIMENTO, R. F.; LIMA, A. C. A.; VIDAL, C. B.; MELO, D. Q.; RAULINO, G. S. C.. Adsorção: aspectos teóricos e aplicações ambientais. Fortaleza: Imprensa Universitária, 2014.

OLIVEIRA, F. M.; COELHO, L. M.; MELO, E. I.. Avaliação de Processo Adsortivo Utilizando Mesocarpo de Coco Verde para Remoção do Corante Azul de Metileno. Matéria, Rio de Janeiro, v.23, n.4, p.1-14, 2018. DOI:

http://dx.doi.org/10.1590/s1517-707620180004.0557

PIZATO, E.; LOPES, A. C.; ROCHA, R. D. C.; BARBOSA, A. M.; CUNHA, M. A. A.. Caracterização de efluente têxtil e avaliação da capacidade de remoção de cor utilizando o fungo Lasiodiplodia theobromae MMPI. Engenharia Sanitária e Ambiental, v.22, n.5, p.1027-1035, 2017. DOI: http://doi.org/10.1590/s1413-41522017121743

PUTRO, J. N.; KUNIAWAN, A.; ISMADJI, S.; JU, Y-H.. Nanocellulose based biosorbents for wastewater treatment:
Study of isotherm, kinetic, thermodynamic and reusability. Environmental Nanotechnology, Monitoring \& Management, v.8, p.134-149, 2017. DOI: http://dx.doi.org/10.1016/j.enmm.2017.07.002

RODRIGUES, A. G.; GALZERANI, J. C.. Espectroscopias de infravermelho, Raman e de fotoluminescência: potencialidades e complementaridades. Revista Brasileira de Ensino de Física, v.34, n.4, p.1-9, 2012. DOI: http://dx.doi.org/10.1590/s1806-11172012000400009

ROCHA, O. R. S.; NASCIMENTO, G. E.; CAMPOS, N. F.; SILVA, V. L.; DUARTE, M. M. M. B.. Avaliação do processo adsortivo utilizando mesocarpo de coco verde para remoção do corante cinza reativo BF-2R. Química Nova, v.35, n.7, 13691374, 2012.

ROCHA, W. D.; LUZ, J. A. M.; LENA, J. C.; ROMERO, O. B. Adsorção de cobre por carvões ativados de endocarpo de noz macadâmia e de semente de goiaba. REM: R. Esc. Minas, Ouro preto, v.59, n.4, p.409-414, 2006. DOI: http://doi.org/10.1590/S0370-44672006000400010

SILVA, A. B. C.; ANDRADE, R. M. F.; FREIRE, F. B.; NAGALLI, A.; CARVALHO, K. Q.; PASSIG, F. H.; KREUTZ, C.. Análise da utilização de cerâmica vermelha como adsorvente na remoção do corante têxtil Direct Blue de uma solução aquosa". Matéria, Rio de Janeiro, v.22, n.3, e11868, 2017. DOI: http://dx.doi.org/10.1590/s1517-707620170003.0202

ZEFERINO, L. F.; FREITAS, P. A. M.. Estudo Cinético Da Adsorção Do Corante Indigo Blue (2,2' - Bis - 2,3 - Diidro - 3 Oxoindolilideno) Em Fibras De Casca De Coco Verde (Cocos Nucifera L). Tese (Doutorado em Engenharia Química) Escola de Engenharia Mauá, Mauá, 2013.

ZHOU, T.; XIA, F.; DENG, Y.; ZHO, Y.. Removal of Pb(II) from aqueous solutions using waste textiles/poly(acrylic acid) composite synthesized by radical polymerization technique. Journal of Environmental Sciences, v.67, p.368-377, 2018. DOI: http://dx.doi.org/10.1016/j.jes.2017.04.010

A CBPC - Companhia Brasileira de Produção Científica (CNPJ: 11.221.422/0001-03) detém os direitos materiais desta publicação. Os direitos referem-se à publicação do trabalho em qualquer parte do mundo, incluindo os direitos às renovações, expansões e disseminações da contribuição, bem como outros direitos subsidiários. Todos os trabalhos publicados eletronicamente poderão posteriormente ser publicados em coletâneas impressas sob coordenação da Sustenere Publishing da Companhia Brasileira de Produção Científica e seus parceiros autorizados. Os (as) autores (as) preservam os direitos autorais, mas não têm permissão para a publicação da contribuição em outro meio, impresso ou digital, em português ou em tradução. 